Jpn. J. Human Genet. 29, 381-385, 1984

\title{
FREQUENCY OF CONSANGUINEOUS MARRIAGES IN JAPAN: GEOGRAPHICAL VARIATIONS
}

\author{
Yoko Imaizumi and Nobuo SHINOzaKI \\ Institute of Population Problems, Ministry of Health and Welfare \\ of Japan, Kasumigaseki, Tokyo 100, Japan
}

Summary The frequency of consanguineous marriages in eight districts of Japan is described based on a nation-wide survey of consanguineous marriages which was conducted on June 1 in 1972 through questionnaires. The rate of first cousin marriages was higher in Kyushu than Hokkaido, Kinki and Shikoku districts in each married year group.

\section{INTRODUCTION}

According to Imaizumi et al. (1975), the frequency of consanguineous marriages decreased as the year of marriage became more recent in the whole of Japan. Geographical variations of the frequency of first cousin marriages were also observed among eight districts in Japan (Imaizumi et al., 1975). In Japan, the data on autosomal recessive diseases are usually collected by university hospitals and localized in many cases. Therefore, to estimate the frequency of autosomal recessive genes based on the local data, the frequency of consanguineous marriages of the local population should be used instead of that of the whole of Japan. In this paper, the frequency of consanguineous marriages in eight districts of Japan is described to give basic data for such studies.

\section{MATERIALS AND METHODS}

The present study utilizes data from the Sixth Fertility Survey conducted on June 1, 1972 by the Institute of Population Problems, Ministry of Health and Welfare, Japan. In the present survey, 300 census enumeration districts were chosen at random out of 2,040 districts which was the master sample and was chosen at random out of 579,709 districts assigned in the 1970 Population Census of Japan (Bureau of Statistics, Office of the Prime Minister). These 300 districts consisted of 219 urban (city) and 81 rural (gun) areas. The total number of relevant couples was 9,525. Questionnaires were distributed to all of them. Of the 9,525 cases,

Received June 26, 1983; revised yersion received July 28, 1984 


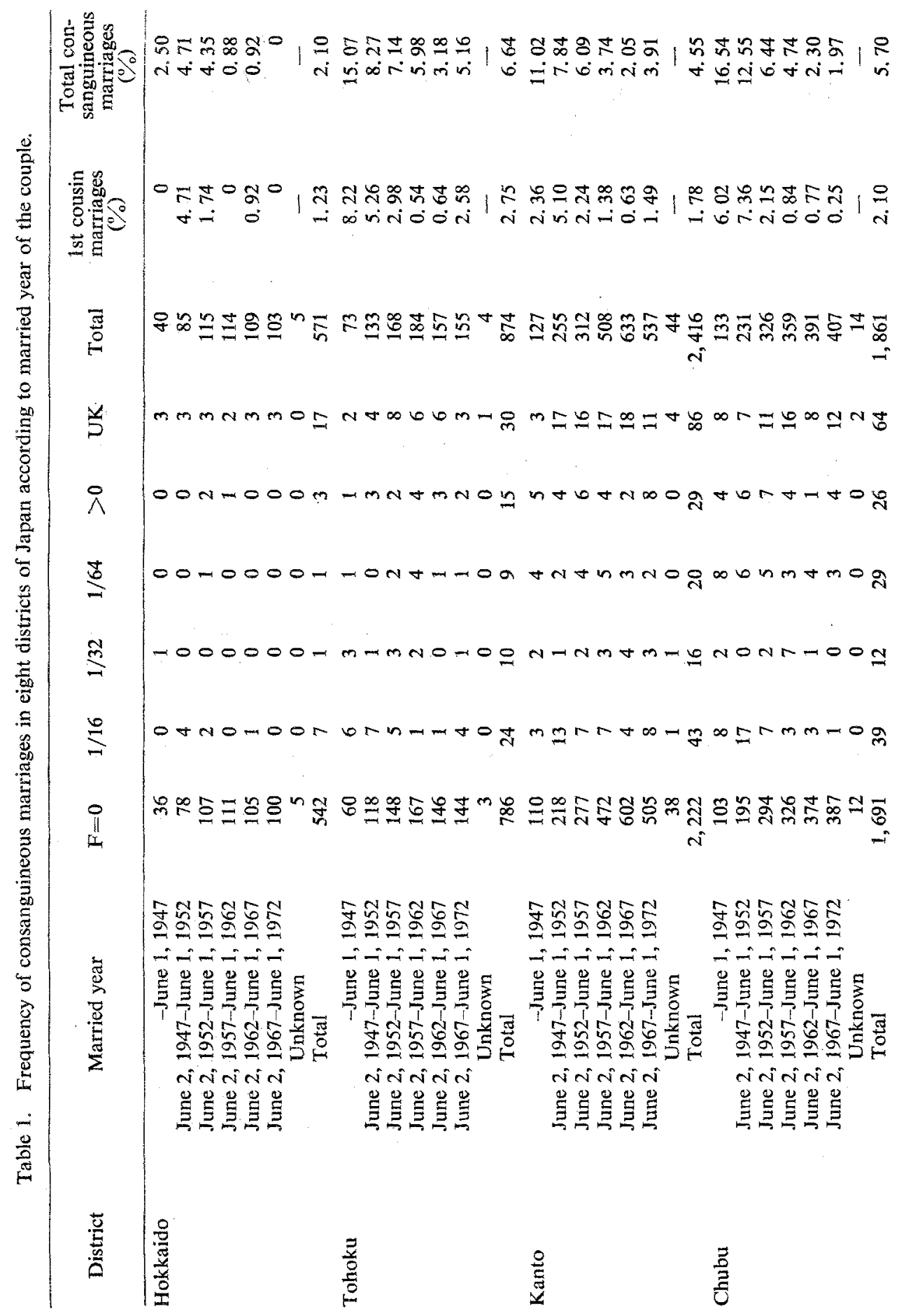




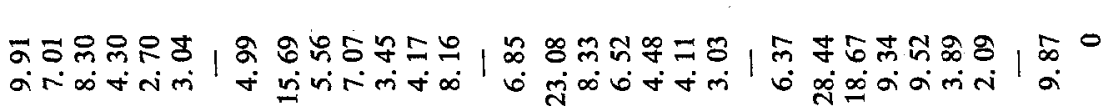

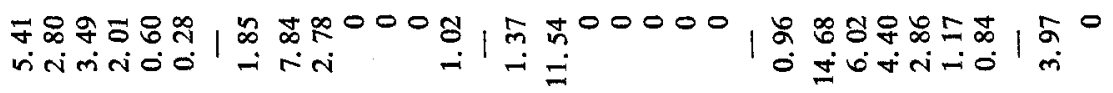

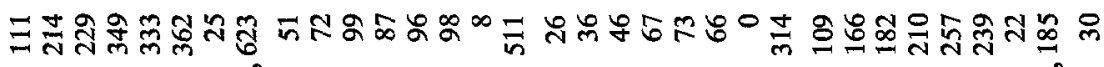

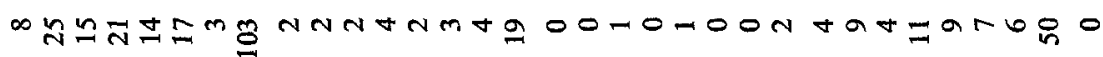

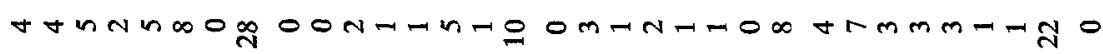

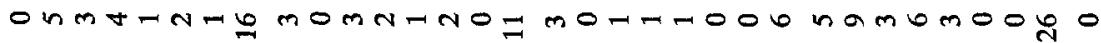

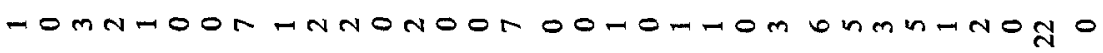

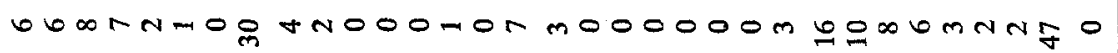

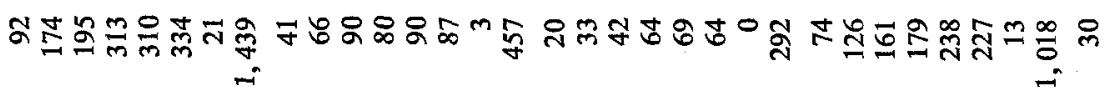

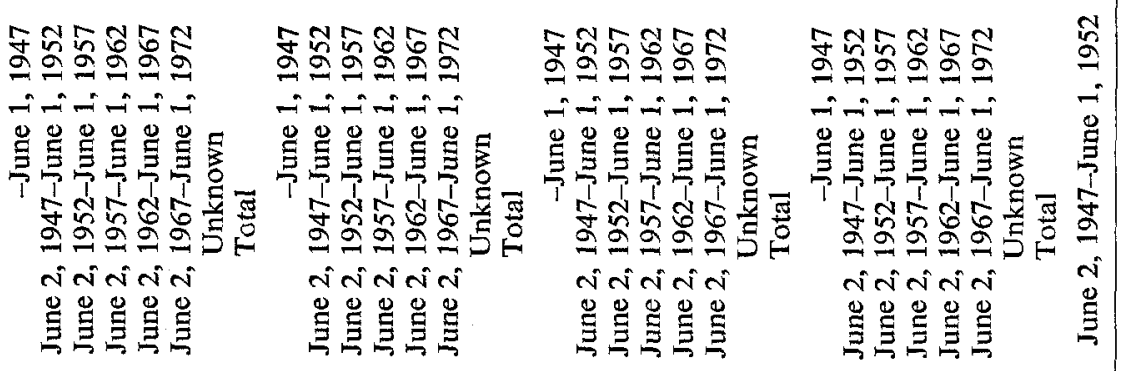

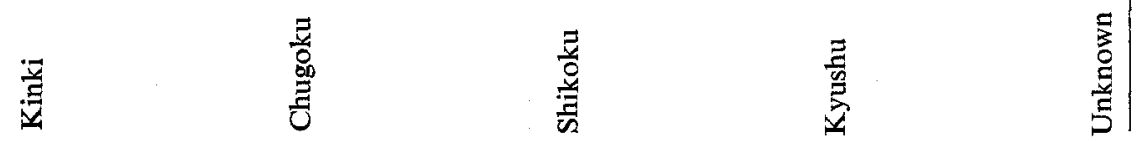
Vol. 29, No. 3, 1984 


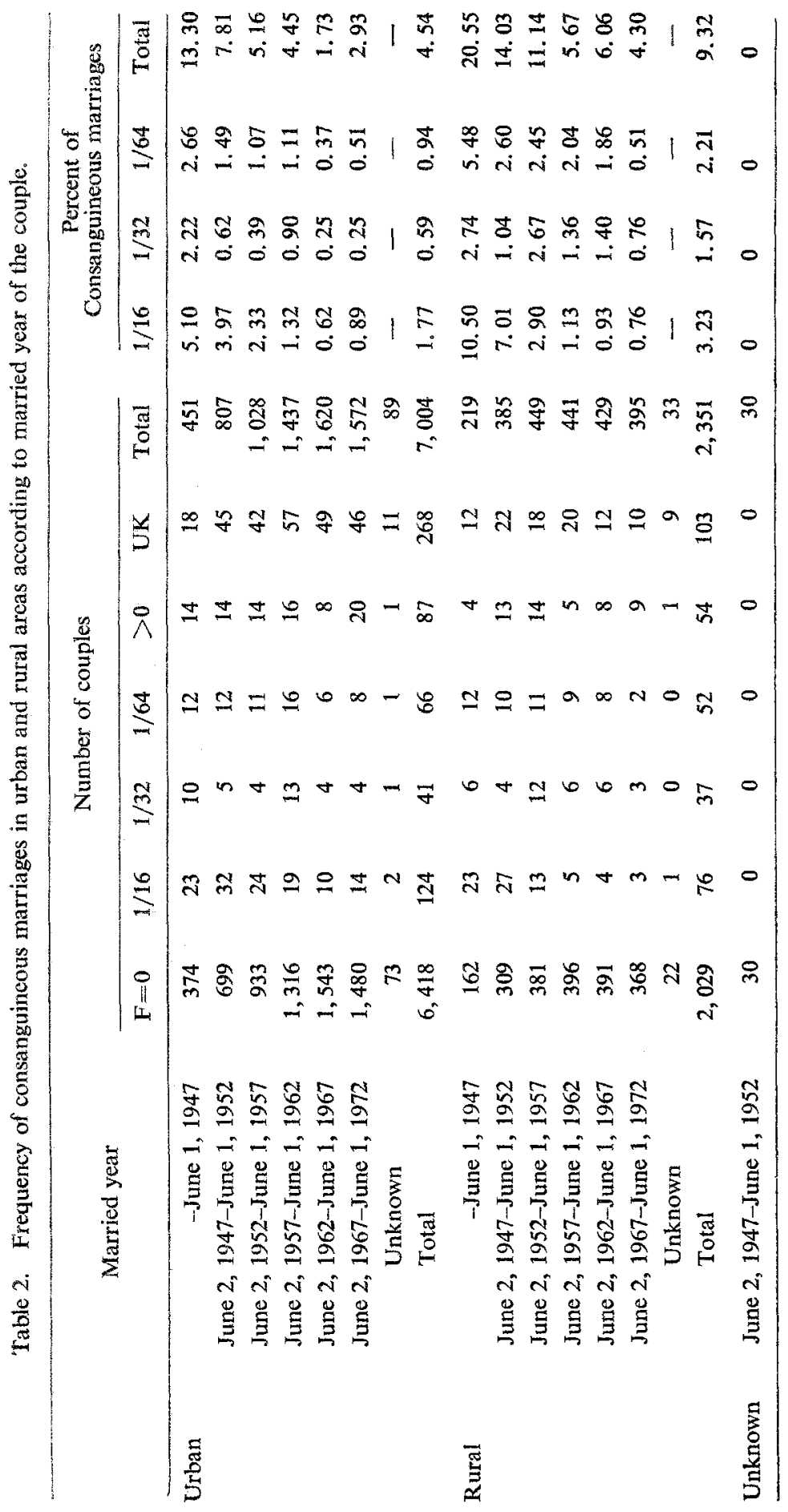


$140(1.5 \%)$ were not returned because of traveling (13), absence (33), hospitalization (2) and/or rejection (92) of the persons questioned. Details of the surveys have been reported elsewhere (Imaizumi et al., 1975).

\section{RESULTS}

Table 1 shows the frequency of consanguineous marriages in each district according to the year the couple was married. In this table, non-related, first cousin, first cousin once removed and second cousin marriages, and consanguineous marriages excluding the above three types of cousin marriages are indicated as $F=0$, $1 / 16,1 / 32,1 / 64$ and $>0$, respectively. The mean rate of first cousin marriages was higher in the Kyushu than in the Hokkaido, Kinki and Shikoku districts in each year group. With one exception the rate in each year group was higher in the Kyushu than in the Tohoku, Kanto, Chugoku and Chubu districts. An exception is seen in the youngest group for the first three districts and in the group of 19471952 for the Chubu district. In the oldest group the mean rate of first cousin marriages was the highest in Kyushu $(14.7 \%$ ) followed by Shikoku $(11.5 \%)$, whereas it was the lowest in Hokkaido $(0 \%)$ followed by the Kanto district $(2.4 \%)$. Therefore, this rate wassix times as large in Kyushu as in the Kanto district. On the other hand, in the youngest group, the mean rate of first cousin marriages was thehighest in the Tohoku district $(2.58 \%)$ followed by the Kanto district $(1.49 \%)$, whereas it was the lowest in Hokkaido $(0 \%)$ and Shikoku $(0 \%)$ followed by the Chubu district $(0.25 \%)$.

Table 2 shows the frequency of consanguineous marriages in urban and rural areas according to year married. Overall frequencies of first cousin, first cousin once removed and second cousin marriages, and other consanguineous marriages were $1.8,2.7,2.3$ and 1.8 times as large in rural as in urban areas, respectively. In the oldest group, frequency of first cousin marriages was $5.1 \%$ in urban areas and $10.5 \%$ in rural areas, whereas in the youngest group the rate of first cousin marriages was under $1 \%$ in both areas. The rate of first cousin marriages rapidly decreased up to 1962 in both urban and rural areas. After this year, the rate was constant and similar in both areas. On the other hand, the rate of second cousin marriages rapidly decreased for the couples married before 1952, but after this year the rate decreased slowly. The rate in urban areas was similar for married couples after 1962, whereas the rate in rural areas was three times higher in the period of 1962-1967 than in the period of 1967-1972. Therefore, the rate declined more quickly in urban than rural areas and in first cousin than second cousin marriages.

\section{REFERENCES}

Imaizumi, Y., Shinozaki, N., and Aoki, H. 1975. Inbreeding in Japan: Results of nation-wide study. Jpn. J. Human Genet. 20: 91-107. 